\title{
Developmental Aspects of Cerebrospinal Fluid Levels of $\beta$-phenylethylamine and It's Role in Pediatric Neurological Disorders
}

\author{
MIKA SATOI \\ Department of Pediatrics and Child Health, Kurume University School of Medicine, \\ Kurume 830-0011, Japan
}

\begin{abstract}
Summary: To clarify the role of $\beta$-phenylethylamine (PEA) in pediatric neurological disorders, we have measured the cerebrospinal fluid (CSF) levels of PEA in 12 children with aseptic meningitis - 6 were in the acute phase and the other 6 were in the recovery phase- and 5 children with Rett Syndrome (RS). The findings were compared with those obtained from 13 age-matched children with leukemia as child controls and from 10 adults patients without any neurological symptoms and signs as control. In the control group, the CSF PEA level was negatively correlated with age until 200 months (17 years) old. The mean PEA levels in meningitis and RS were significantly lower than that of child controls $(p<0.03)$. The alteration in the CSF levels of PEA may be related to transient changes in the dopaminergic tone in aseptic meningitis and neurological impairment, especially in the dopaminergic neurons in RS.
\end{abstract}

Key words $\beta$-phenylethylamine, cerebrospinal fluid, meningitis, Rett syndrome

\section{INTRODUCTION}

$\beta$-phenylethylamine (PEA) was identified as a biogenic trace amine in mammalian tissues including brain in the 1960s [1,2]. Since then, PEA has been investigated extensively in neurochemical, neuropharmacologic and neurophysiologic contents [3-7]. PEA is synthesized by decarboxylation of phenylalanine at dopaminergic neurons of the nigrostriatal system [8,9]. PEA is metabolized by monoamine oxidase type B (MAO-B) to phenylacetaldehyde, and then further metabolized by aldehydedehydrogenase to phenylacetic acid (PAA) or by dopamine- $\beta$ hydroxylase to phenylethanolamine [10] (Fig 1). The role of PEA in the human brain is still unknown [6]. It has been considered to be difficult to measure the CSF levels of PEA, because the level in human CSF has been suggested to be very low, due to its rapid turn over [3].

Recently, Zhou et al. has determined the CSF levels of PEA in Parkinson disease (PD) and found a negative correlation between PEA level and the severity of PD [11].

The PEA level in the CSF of children has not been reported. In the present study, we have established the methodology to measure the CSF levels of PEA using gas chromatography-chemical ionizationmass spectrometry $(\mathrm{GC} / \mathrm{CI} / \mathrm{MS})$. Here, we report the CSF levels of PEA in children with meningitis (including those at the acute phase and those at the recovery phase), RS, and control.

\section{PATIENTS AND METHODS}

\section{Patients}

We measured the CSF PEA levels in 12 children with aseptic meningitis ( 6 male and 6 female, mean

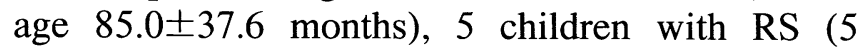

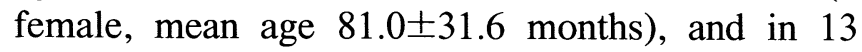
children with leukemia as control $(5$ male and 8 female, mean age $84.2 \pm 39.3$ months), and 10 normal adults as additional controls (4 male and 6 female, mean age 589.2 \pm 170.8 months). Specimens 


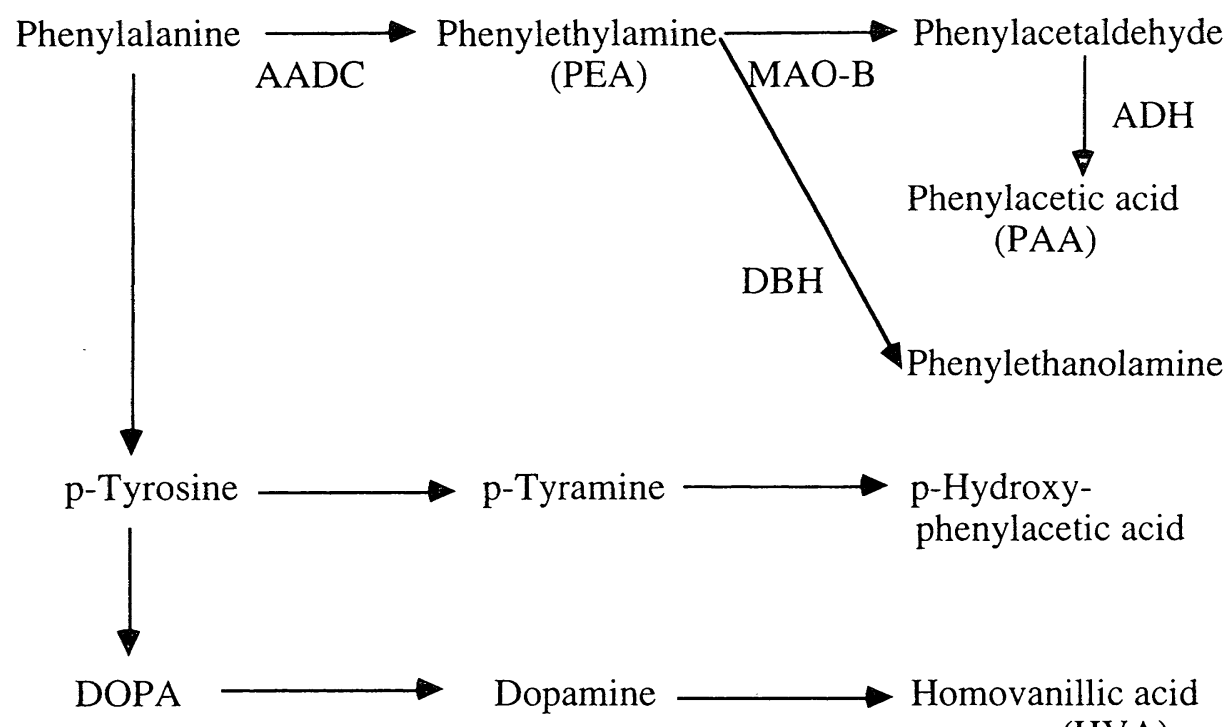

(HVA)

Fig. 1. Synthesis and catabolism of phenylethylamine and dopamine.

AADC: aromatic amino acid decarboxylase; MAO-B: monoamine oxidase type B; DBH: dopamine $\beta$-hydroxylase; DOPA: 3,4-dihydroxyphenylalanine

TABLE 1.

Cerebrospinal fluid levels of PEA levels in control group

\begin{tabular}{cccrl}
\hline $\begin{array}{c}\text { Patient } \\
\text { Number }\end{array}$ & $\begin{array}{c}\text { Age } \\
(\text { months })\end{array}$ & Sex & $\begin{array}{c}\text { PEA } \\
(\mathrm{pg} / \mathrm{ml})\end{array}$ & Leukemia \\
\hline 1 & 111 & male & 523.1 & LRALL \\
2 & 123 & male & 833.1 & NHL \\
3 & 105 & female & 1276.3 & LRALL \\
4 & 32 & female & 1580.0 & LRALL \\
5 & 75 & female & 1074.4 & LRALL \\
6 & 58 & male & 773.8 & LRALL \\
7 & 150 & male & 510.4 & LRALL \\
8 & 120 & female & 754.1 & LRALL \\
9 & 30 & female & 1346.1 & LRALL \\
10 & 61 & male & 1167.2 & LRALL \\
11 & 119 & female & 404.6 & LRALL \\
12 & 42 & female & 1901.5 & LRALL \\
13 & 68 & female & 951.6 & LRALL \\
\hline
\end{tabular}

PEA: phenylethylamine

LRALL: low risk group of acute lymphoblastic leukemia

NHL: non Hodgikin lymphoma

of the CSF were obtained with the written informed consent of subjects' parents or of the patients themselves. The permission procedure and the study design was approved by the Medical Ethics Committee of Kurume University Hospital. Lumbar puncture for the collection of $3 \mathrm{ml} \mathrm{CSF}$ was performed between 10:00 am and 12:00 noon without local or general anesthesia. A 2-ml aliquot of CSF was used for the cell count, for measurements of glucose, protein, and for culture. The remaining $1 \mathrm{ml}$ was immediately frozen and stored at $-80^{\circ} \mathrm{C}$ for the assay of PEA levels.

Child control: The controls consisted of 13 children with leukemia at low risk involving 12 children with acute lymphoblastic leukemia (LRALL), and 1 with non-Hodgikin lymphoma (NHL) aged 2 to 13 years 
TABLE 2

Cerebrospinal fluid levels of PEA in children with Rett Syndrome

\begin{tabular}{ccccc}
\hline $\begin{array}{c}\text { Patient } \\
\text { Number }\end{array}$ & $\begin{array}{c}\text { Age } \\
\text { (months) }\end{array}$ & Sex & Stage & $\begin{array}{c}\text { PEA } \\
(\mathrm{pg} / \mathrm{ml})\end{array}$ \\
\hline 1 & 61 & female & III & 978.0 \\
2 & 65 & female & III & 155.3 \\
3 & 69 & female & III & 219.1 \\
4 & 73 & female & III & 29.1 \\
5 & 137 & female & IV & 276.3 \\
\hline
\end{tabular}

Clinical stage was diagnosed according to the Rett Syndrome Diagnostic Criteria Work Group [12]

(Table 1). They received lumbar puncture in the course of their treatment. The CSF findings for the standard parameters were normal, and they had none of the neurological signs nor symptoms.

Adult control: There were 10 adult controls without any neurological diseases or condition, involving 5 orthopedic patients, 2 urologic patients, 2 gynecologic patient, and 1 other.

Aseptic meningitis: There were 12 children with aseptic meningitis, who were diagnosed by clinical and CSF findings. They were hospitalized with chief complaints of fever, headache and/or vomiting. All of the patients were well nourished and had not received any neurological or psychiatric medication. Of these, 6 were in the acute phase having high fever, vomiting, and CSF pleocytosis (cell count range, 30 to $500 / \mathrm{mm}^{3}$ ), and 6 were in the recovery phase, being non free from symptoms of fever, headache and vomiting and with normalized CSF findings. None of them had any neurological complication or sequela.

Rett syndrom: Five patients were diagnosed as having typical Rett Syndrome, according to the Rett Syndrome Diagnosed Criteria Work Group (1988) [12]. All the patients were female, and none had received naltrexone -an opiate peptide antagonistor anti-convulsants. Of these, 4 were at stage III and 1 was with stage IV (Table 2).

\section{Assay procedure of $\beta$-phenylethylamine}

The extraction of PEA from CSF was performed by a method described previously [13]. The $1.0 \mathrm{ml}$ specimen of CSF was placed in a silicon coated tubes. Then $1 \mathrm{ng}$ of $\mathrm{D}_{4}$-PEA (MSD ISOTOPES, Montreal, Canada) was added to the tube as an internal standard. In addition, $30 \mu \mathrm{l}$ of Ringer's solution was added. Then, 30 pg, 100 pg, 300 pg, 1000 pg of PEA were each added to one of these four tubes as standard. All samples were kept at $0{ }^{\circ} \mathrm{C}$ for $20 \mathrm{~min}$ to equilibrate. Following the addition of 50 $\mu 1$ of $6 \mathrm{~N} \mathrm{NaOH}, \mathrm{CSF}$ was applied to an Extrelut column $(2 \mathrm{~cm} \times 2.5 \mathrm{~cm}$, Merk, Germany) for $5 \mathrm{~min}$, and was eluted with $7 \mathrm{ml}$ ethylacetate. The eluate was collected in a tube which contained $100 \mu \mathrm{l}$ of 1 $\mathrm{mM} \mathrm{HCl}$ to the eluate before evaporation not to evaporate PEA and evaporated by a Sreed Vac Concentrator (Savant, USA). The residue was derivatized with $50 \mu \mathrm{l}$ of pentafluoropropionate (PFP) anhydride (Tokyo Kasei Co., Tokyo, Japan) at $60{ }^{\circ} \mathrm{C}$ for $20 \mathrm{~min}$. The solvent was evaporated to dryness with dry nitrogen gas, and the sample was reconstituted with $20 \mu 1$ ethylacetate. Sample volumes of 2 $\mu l$ were injected into Gas chromatography-chemical ionization-mass spectrometry (GC/CI/MS). The double-focused mass spectrometer was interfaced with a data acquisition system (Hitachi M-80B, Hitachi, Japan). Isobutane was used as the reagent gas (source pressure, $3 \times 10^{-6}$ forr) and helium was used for the $\mathrm{GC}$ carrier gas $(40 \mathrm{ml} / \mathrm{min})$. The oven temperature was maintained isothermally at $115{ }^{\circ} \mathrm{C}$. The mass numbers used for quantitative analysis were $\mathrm{m} / \mathrm{z} 268$ corresponding to PEA-PFP and $\mathrm{m} / \mathrm{z}$ 272 corresponding to D4-PEA-PFP (Fig. 2). The peak area was used for the estimation of ion currents. The calibration curve was highly correlated in standard samples $(r=0.98)$ in the range of $10 \sim 300$ pg/ml PEA (Fig. 3).

A statistical comparison between the RS and control was performed with Student's t-test (two tailed) for subjective data. The correlation between the level of PEA and age or clinical stage was calculated using Pearson's correlation coefficient. A p-value less than 0.05 was regarded as a significant difference. 


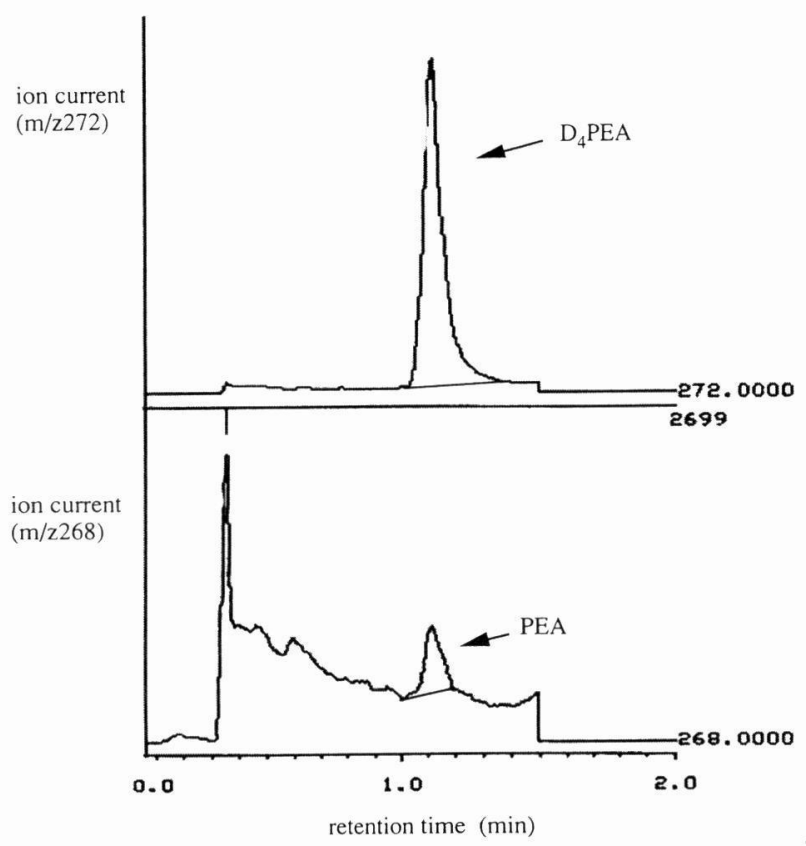

Fig. 2. Typical SIM Chromatogram, showing the recordings of pentafluoropropionic derivative of phenylethylamine $(\mathrm{m} / \mathrm{z} 268$, lower part) with a deuterium-labeled internal standard $(\mathrm{m} / \mathrm{z} \quad 272$, upper part), obtained from $1.0 \mathrm{ml}$ of CSF.

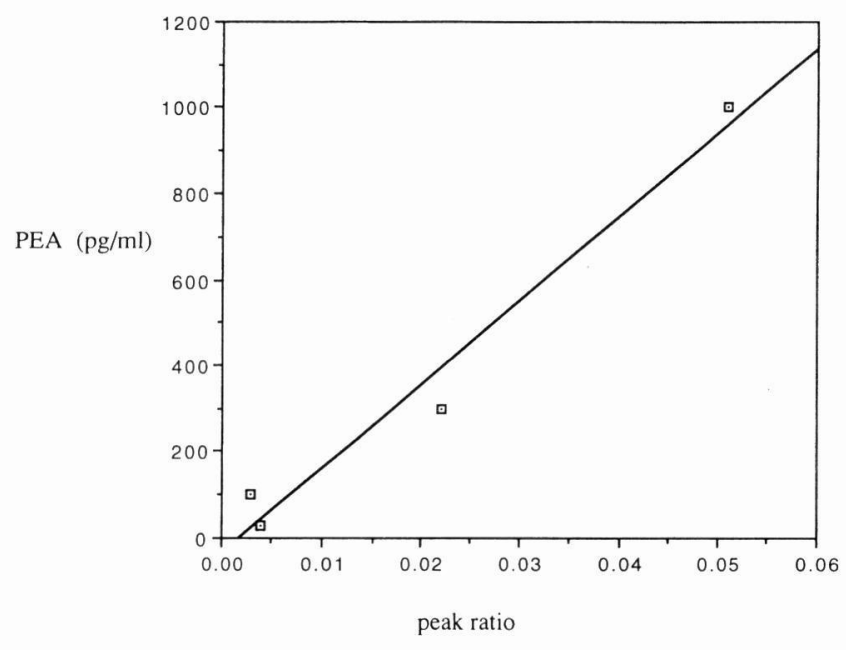

Fig. 3. Calibration curve for selected ion monitoring chromatographic analysis of phenylethylamine extracted from Ringer's solution. Horizontal axis represents ion intensity ratio of m/z 268 to $\mathrm{m} / \mathrm{z} 272$.

\section{RESULTS}

\section{Control}

The mean CSF level of PEA was 936.23 \pm 143.99 in child control. The relationship between age and CSF PEA levels in the control was shown in Fig. 4. The levels were significantly negative correlated with increasing ages to 200 months $(\mathrm{p}=0.032)$. There was no significant sex difference in the PEA level.

\section{Aseptic meningitis}

The CSF levels of PEA were significantly decreased in the acute phase and in the recovery phase of aseptic meningitis, compared to that of agematched controls (Fig. 5). The PEA level in the acute phase $(81.85 \pm 15.54 \mathrm{pg} / \mathrm{ml})$ was significantly lower than that in the children in the recovery phase (200.35 $\pm 34.19 \mathrm{pg} / \mathrm{ml}),(\mathrm{p}=0.016)$.

\section{Rett syndrome}

The mean PEA level in CSF of children with RS was $331.54 \pm 166.75 \mathrm{pg} / \mathrm{ml}$. The level was significantly lower than that of child controls $(\mathrm{p}=0.020)$ (Fig. 6). The CSF level of PEA was not correlated with clinical stage. 


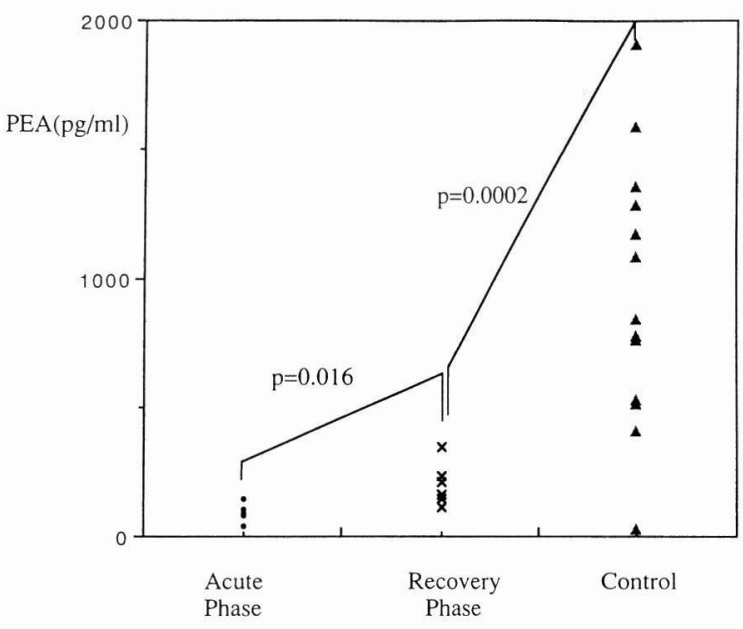

Fig. 5. Comparison of CSF PEA level among acute phase, recovery phase in aseptic meningitis and control. The CSF PEA level in acute phase was significantly decreased compared to those in recovery phase of aseptic meningitis $(\mathrm{p}<0.02)$. And the levels in the both phases were significantly lower than controls $(\mathrm{p}<$ $0.01)$.

\section{DISCUSSION}

Some studies have indicated that PEA acted as a neurotransmitter or neuromodulator in the nigrostriatal dopaminergic pathway [6]. PEA, which has been implicated in the pathogenesis of certain psychiatric and neurological diseases, has been identified as a biogenic trace amine in mammalian tissues including brain in the 1960s [1,2].

Acting on dopamine transporters on dopaminergic terminals, PEA stimulates release of dopamine [4,14-16]. PEA also has an indirect sympathomimetic effect [17]. Some researchers have reported a change in PEA concentrations in psychiatric diseases. Urinary PEA excretion is significantly higher in paranoid chronic schizophrenia than in non paranoid chronic schizophrenia and normal controls [18]. Decreased urinary levels of PEA have been reported in patients with depression [19,20]. Urinary levels of free PEA were decreased in Tourette's syndrome patients [21], and attention deficit hyperactive disorder [22], compared to values in normal children. In the present study, a control value was obtained from children with leukemia. It is difficult to perform lumber puncture in children without any symptoms of central nervous infections. In order to exclude some factors (fever, anti convulsants, infections of central nerves system and others) which might influence alterations in the CSF PEA level, the CSF

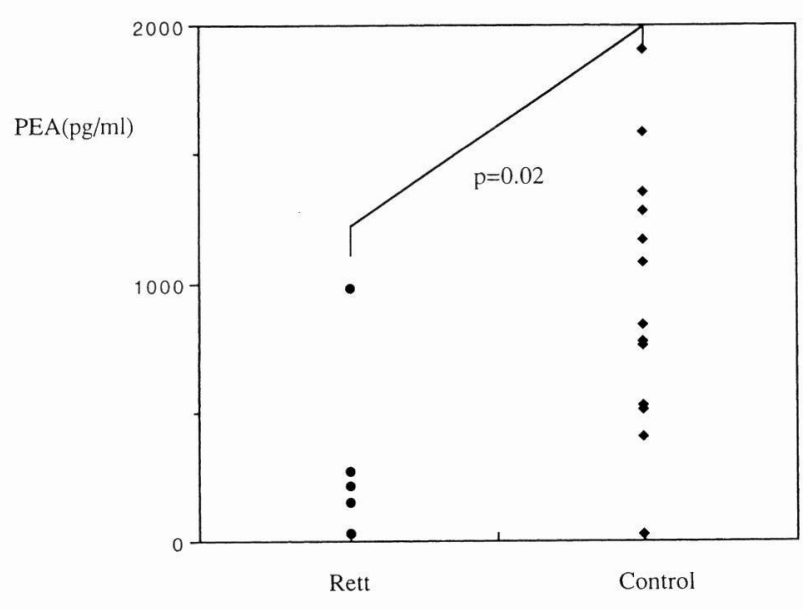

Fig. 6. Comparison of CSF PEA level of children with Rett syndrome (RS) with those of controls. The PEA level of CSF with RS was significantly lower than child control $(\mathrm{p}<0.03)$.

of children with leukemia appeared to be adequate. Patients with acute lymphoblastic leukemia (ALL) without CNS impairement have been suggested as suitable for control purposes, previously [23], and have been employed here.

The most remarkable findings from this study were the marked reduction in the PEA levels in the CSF in aseptic meningitis compared to the controls $(p<0.01)$. Moreover, the CSF level in acute phase was significantly lower than that in the recovery phase $(p<0.02)$. Komori et al. reported that the CSF biopterin level in the acute phase was significantly higher than that in the recovery phase [24]. Biopterin is a cofactor for key enzymes in the synthesis of dopamine and serotonin, and some cytokines can induce biopterin production and increase the CSF levels of homovanillic acid (HVA). They reported that the CSF levels of both HVA and 5-hydroxyindoleacetic acid (5-HIAA) were remarkably elevated in the acute phase of aseptic meningitis [24]. The dopamine level of CSF in the acute phase of aseptic meningitis might be increased and PEA might be reduced by phenylalanine expended, or by presynaptic inhibition of aromatic acid decarboxylase due to increased dopamine levels. Yamada et al. reported that PEA could modify DA autoreceptor mediated changes in evoked DA released in rat [25]. Rodriguez et al. reported that endogenous PEA levels regulated the nigrostriatal dopaminergic cell activity 
[26].

The present report is the first to determine the CSF level of PEA in Rett syndrome; the CSF PEA level in RS was lower than that of control, and the level was independent of age, and of clinical stage. There are several reports regarding the levels of biogenic amine metabolites in CSF in RS. Zoghbi et al. reported significant reductions in homovanillic acid (HVA) and 3-methoxy-4-hydroxyphenylethylene glycol (MHPG) in the CSF in RS compared to age-matched controls [27]. On the other hand, Leckman reported no difference between patients with RS and controls [28]. Thus, the alterations in the CSF levels of biogenic amines and of these metabolites in RS is not yet established. Recently, Zhou et al. reported that the CSF PEA level in PD was significantly lower than that in controls, and that the PEA level in PD was negatively correlated with clinical severity [11]. These results suggested that dopaminergic neuronal degeneration could cause a reduction in the CSF level of PEA [4,6,29].

The pathogenesis of $\mathrm{RS}$ is considered to be dopaminergic neuron dysmaturation which could explain the low level of PEA in RS [30]. However the CSF level of PEA in RS did not vary with increasing age, or according to clinical stage. There are two possibilities to account for the observed decreased CSF levels of PEA in RS; involving either a high activity of MAO-B which catabolizes PEA to PAA, or low activity of aromatic acid decarboxylase that inhibits PEA synthesis in the decarboxylation step (Fig. 1). Some researchers have suggested that the level of PEA or its metabolite phenylacetic acid (PAA) may be a useful biochemical marker in psychiatric and behavioral research [18,31].

In RS, the biological marker has not been yet established. Thus CSF measurements of PEA might be a candidate biological marker to diagnose RS.

ACKNOWLEDGMENTS: The author wishes to thank Professor Hirohisa Kato for reading an earlier draft, and Assistant Professors T. Matsuishi and S. Yamada for their technical advice. The author also thanks Dr. K. Ichikawa, Yahata Municipal Hospital, Dr. T. Fujimoto, Fujimoto Children's Hospital, and Dr. T. Nishimi, St. Mary's Hospital for collecting and providing the cerebrospinal fluid specimens.

\section{REFERENCES}

1. Fuxe $\mathrm{K}$, Grobecker $\mathrm{H}$, and Jonson J. Effect of $\beta$ phenylethylamine on central and peripheral monoaminecontaining neurons. Eur J Phamacol 1967; 2:203-207.

2. Durden DA, Philips SR, and Boulton AA. Identification and distribution of $\beta$-phenylethylamine in the rat. Can $\mathbf{J}$ Biochem 1973; 51:995-1002.

3. Durden DA, and Philips SR. Kinetic measurements of the turnover rates of phenylethylamine and tryptamine in vivo in the rat brain. J Neurochem 1980; 34:1725-1732.

4. Philips SR, and Robson AM. In vivo release of endogenous dopamine from rat caudate nucleus by phenylethylamine. Neuropharmacology 1983; 22:1297-1301.

5. Rao TS, Baker GB, and Coutts RT. N-Dipropargy-2phenylethylamine, a potentprodrug of 2-phenylethylamine: neurochemical and neuropharmacological studies in rat. Brain Res Bull 1987; 19:47-55. 27.

6. Paterson IA, Juorio AV, and Boulton AA. 2-Phenylethylamine: a modulator of catecholamine transmission in the mammalian central nervous system? J Neurochem 1990; 55:1827-1837.

7. Knoll J, Miklya I, Knoll B, Marko R, and Racz D. Phenylethylamine and tyramine are mixed-acting sympathomimetic amines in the brain. Life Sci 1996; 58:21012114.

8. Dyck LE, Yang CR, and Boulton AA. The biosynthesis of p-tyramine, $\mathrm{m}$-tyramine, and $\beta$-phenylethylamine by rat striatal slices. J Neurochem Res 1983; 10:211-220.

9. Juorio AV, Paterson IA, Zhu MY, and Matte G. Electrical stimulation of the substantia nigra and changes of 2-phenylethylamine synthesis in the rat striatum. J Neurochem 1991; 56:213-220.

10. Wu PH, and Boulton AA. Metabolism, distribution and disappearance of injected $\beta$-phenylethylamine in the rat. Can J Biochem 1975; 53:42-50.

11. Zhou G, Shoji H, Yamada S, and Matsuishi T. Decreased cerebrospinal fluid $\beta$-phenylethylamine in Parkinsons' disease. J Neurol Neurosurg Psychiatry 1997; 63:754-758.

12. The Rett Syndrome Diagnostic Criteria Work Group. Diagnostic criteria for Rett syndrome. Ann Neurol 1988; 23:425-428.

13. Yamada S, Hirano M, Nshi S, Inokuchi T, and Uchimura H. Temperament traits associated with platelet monoamine oxidase activity and plasma 2-phenylethylamine in healthy volunteers. Biogenic Amines 1994; 10:295-302.

14. Antelman SM, Edwards DL, and Lin M. Phenylethylamine: Evidence for a direct, postsynaptic dopaminereceptor stimulating action. Brain Res 1977; 127:317-322.

15. Raiteri M, Del Carmine R, Berlollini A, and Levi G. Effect of sympathomimetic amines in the synaptosomal transport of noradrenaline, dopamine, and 5-hydroxytryptamine. Eur J Pharmacol 1977; 41:133-143.

16. Bailey BA, Philips SR, and Boulton AA. In vivo release of endogenous dopamine, 5-hydroxytryptamine and some of their metabolites from rat caudate nucleus by phenylethylamine. Neurochem Res 1987; 12:173-178.

17. Henwood RW, Boulton AA, and Phillis JW. Iontophoretic studies of some trace amine, and 5-hydroxytryptamine. Eur J Pharmacol 1977; 41:133-143.

18. Potkin SG, Karoum F, Chuang LW, Cannon-Spoor HE, Phillips I et al. Phenylethylamine in paranoid chronic scizophrenia. Science 1979; 206:470-471.

19. Sabelli HC, Fawcett J, Gusovsky F, Javaid J, Edwards J et al. Urinary phenylacetate: a diagnostic test for depression? Science 1983; 225:1187-1188. 
20. Davis BA, and Boulton AA. The trace amines and their acidic metabolites in depression -an overview. Prog Neuropsychopharmacol Biol Psychiatry 1994; 18:17-45.

21. Bornsterin RA, and Baker GB. Neuropsychological performance and urinary phenylethylamine in Tourette's syndrome. J Neuropsychiatry Clin Neurosci 1991; 3:417421.

22. Baker GB, Bornstein AC, Rouget AC, Ashton SE, van Muyden JC et al. Phenylethylaminergic mechanisms in attention-deficit disorder. Biol Psychiatry 1991; 29:1522.

23. Nielsen JB, Bertelsen A, and Lou HC. Low CSF HVA levels in Rett Syndrome: a reflection of restricted synapse formation? Brain Dev 1992; 14:63-65.

24. Komori H, Matsuishi T, Yamada S, Ichikawa $\mathrm{K}$, Amamoto $\mathrm{M}$ et al. Elevated biopterin and homovanillic acid levels in cerebrospinal fluid from children with aseptic meningitis. J Child Neurol 1994; 9:22-25.

25. Yamada S, Harano $M$, and Tanaka M. Antagonistic effects of $\beta$-phenylethylamine on quinpirole- and -sulpiride induced changes in evoked dopamine release from the rat striatal slices. Eur J Pharmacol 1998; 343:145-150.

26. Rodriguez $\mathrm{M}$, and Barroso $\mathrm{N}$. beta-Phenylethylamine regulation of dopaminergic nigrostriatal cell activity. Brain Res 1995; 703:201-204.

27. Zoghbi H, Milstien H, Butler IJ, Smith OB, Kaufman S et al. Cerebrospinal fluid biogenic amines and biopterin in Rett Syndrome. Ann Neurol 1989; 25:56-60.

28. Lekman A, Witt-Engerström I, Gottfries J, Hagberg B, Percy AK et al. CSF and urine biogenic amine metabolites in Rett syndrome. Clin Genet 1990; 37:173-178.

29. Reynolds GP, Sandler M, Hardy J, and Bradford H. The determination and distribution of 2-phenylethylamine in sheep brain. J Neurochem 1980; 34:1123-1125.

30. Armstrong DD. The neuropathology of the Rett syndrome. Brain Dev 1992; 14:89-98.

31. Faull KF, Pascoe N, Greene KA, and Maddaluno JF. Measurement of phenylacetic acid in cerebrospinal fluid and plasma using combined gas chromatography/electron capture chemical ionization mass spectrometry. Biomed Environ Mass Spectrom 1988; 17:213-219. 